\title{
An intervention strategy for improving residential environment and positive mental health among public housing tenants: rationale, design and methods of Flash on my neighborhood!
}

\author{
Janie Houle ${ }^{1 *}$ (D) Simon Coulombe ${ }^{2}$, Stephanie Radziszewski ${ }^{1}$, Xavier Leloup ${ }^{3}$, Thomas Saïas ${ }^{1}$, Juan Torres ${ }^{4}$
} and Paul Morin ${ }^{5}$

\begin{abstract}
Background: In Canada, public housing programs are an important part of governmental strategies to fight poverty and public exclusion. The Flash on my neighborhood! project is a four-year multiphase community-based participatory action research strategy currently implemented in six public housing developments ( $n=1009$ households) across the province of Québec, Canada. The goal is to reduce the mental health disparities faced by these public housing tenants compared to the general population, while identifying which environmental and policy changes are needed to turn public housing settings into healthier environments.

Methods: The protocol involves three successive, interconnected phases: 1) Strengths and needs assessment, including community outreach and recruitment of tenants to collaborate as peer researchers, an exploratory qualitative component (photovoice), a systematic neighborhood observation, and a household survey; 2) Action plan development, including a community forum and interactive capacity-building and discussion sessions; 3) Action plan implementation and monitoring. The entire intervention is evaluated using a mixed-method design, framed within a multiple case study perspective. Throughout the project and particularly in the evaluation phase, data will be collected to record a) contextual factors (tenants' previous experience of participation, history of public housing development, etc.); b) activities that took place and elements from the action plan that were implemented; and c) short- and mediumterm outcomes (objective and perceived improvements in the quality of the residential setting, both physically and in terms of mental health and social capital).

Discussion: The study will provide unprecedented evidence-based information on the key ingredients of a collective intervention process associated with the increased collective empowerment and positive mental health of public housing tenants.
\end{abstract}

Keywords: Place-based intervention strategy, Positive mental health, Empowerment intervention, Residential environment, Public housing

\footnotetext{
* Correspondence: houle.janie@uqam.ca

'Department of Psychology, Université du Québec à Montréal, C.P. 8888,

succ. Centre-ville, Montréal, Québec H3C 3P8, Canada

Full list of author information is available at the end of the article
} 


\section{Background}

The ultimate goal of the intervention discussed in this manuscript, Flash on my neighborhood!, is to reduce mental health inequalities faced by public housing tenants. In Canada, the public housing program is an important component of governmental strategies to fight against poverty and social exclusion. In the province of Quebec, households who live in public housing developments pay only $25 \%$ of their income as rent, the remaining being funded by the government. There were close to 74,000 households benefiting from this program in Québec in 2011 [1]. Differently than in other countries, public housing is considered to be a residual housing option in Canada. Only people living in poverty have access to this program. Furthermore, in Québec, the largest proportion of public housing tenants is made of elderly people, mostly living in buildings that are reserved to this population.

Even if they have access to an affordable dwelling, public housing tenants suffer from a higher burden of physical and mental disease and have lower well-being and life expectancy than the general population [2-6]. Public housing tenants are a vulnerable population in the sense intended by Frohlich and Potvin (p. 218): "a subgroup or subpopulation who, because of shared social characteristics, is at higher risk of risks. The notion of vulnerable populations refers to groups who, because of their position in the social strata, are commonly exposed to contextual conditions that distinguish them from the rest of the population." [7] Accessibility to public housing is restricted to low-income people (mostly living on social assistance benefits) presenting cumulative vulnerabilities, such as single parenthood, physical and mental disorders, recent immigration, large family size, and exclusion from the job market, or precarious and low paid jobs. Limiting public housing to a highly vulnerable portion of the population increases tenants' stigmatization by other citizens [8-10].

A focus group study conducted among public housing tenants $(n=28)$ in Baltimore showed how social isolation was pervasive in this residential environment, possibly influenced by the lack of trust between neighbors, and how tenants viewed increasing neighborhood social capital as a promising strategy to their improve wellbeing [11]. Research suggests that the built environment is also often problematic, as public housing generally consists of multi-storey buildings ${ }^{1}$ that are poorly soundproofed and ventilated, over-crowded, and regularly infested by vermin $[8,11-13]$.

Social and physical aspects of the residential environment, including the apartment, building, and neighborhood, are important determinants of physical and mental health $[14,15]$, especially for people living in poverty who are generally limited in their daily mobility due to financial constraints and exclusion from the job market $[16,17]$. They spend an important proportion of their time in their house and neighborhood [18], and are thus considered a locally-dependent group [19]. Public housing settings have the potential to be healthpromoting environments that contribute to lessening social health inequalities instead of increasing them. However, this potential is often not fully exploited as public housing programs are often limited to providing shelter, without fully considering all the aspects that can contribute to (or hinder) tenants' positive mental health. The present study focuses on the mental health-promoting potential of public housing settings, by implementing and evaluating an empowerment-based participatory intervention that aims to enhance public housing tenants' mental health by engaging their community in a process focused on improving their residential environment.

Social health inequalities have been described extensively and comprehensively [20,21]. A social gradient is observed for almost all diseases and causes of death, including mental disorders [22-25]. Empirical evidence suggests that socioeconomic status influences health through the activation of the chronic social stress response, which creates a detrimental allostatic load, linked to a variety of diseases, including cardiovascular disease, diabetes, cancer, and depression [26-32]. Several decades of research have repeatedly identified control over one's life and social capital as important mediators of the physiological impact of chronic social stress [33, 34]. Social capital is defined by Bourdieu (p. 248-249) as "the aggregate of the actual or potential resources which are linked to possession of a durable network of more or less institutionalized relationships of mutual acquaintance or recognition." [35] Based on this body of research, it has been hypothesized that, in order to reduce social health inequalities, interventions should increase the level of control people from low social status have over their life, as well as their social capital [15, 32, 36, 37].

Previous public health intervention research in public housing settings primarily focused on the reduction of risk factors for physical diseases, such as smoking, physical inactivity, and insufficient fruit and vegetable intake [38-42]. Until now, mental health has been neglected by interventions designed to reduce social health inequalities. Among the 319 studies identified in a recent systematic review of community engagement interventions to reduce health inequalities, only three focused on mental health, and none of those on interventions being implemented in a public housing setting [43]. Improving mental health among public housing tenants should be prioritized, since a person who enjoys good mental health "realizes his or her own potential, can cope with the normal stresses of life, [...] and is able to make a contribution to her or his community". [44] Furthermore, people in good 
mental health are more prone to adopt a healthy lifestyle [45-48] and are likely to be more successful in quitting bad habits such as smoking [49].

Mental health is more than the absence of illness, it also includes a state of well-being. Indeed, empirical evidence suggests that mental illness and positive mental health are two distinct constructs (although they are somewhat correlated) $[50,51]$, and that improvement in positive mental health predicts a decline in mental illness over time [52]. Positive mental health includes two aspects of well-being: 1) a hedonic aspect, which relates to having pleasurable experiences, such as being satisfied with one's life and feeling more positive than negative emotions; and 2) an eudaimonic aspect, which refers to feeling that one's life is meaningful, and to thriving through fulfilling relationships and engagement that contributes to society $[50,53]$. High positive mental health, particularly positive relations with others and purposeful engagement, has been found to be related to lower biological markers of chronic stress, all-cause mortality, cardiovascular events, and stroke [54-57]. On the other hand, material deprivation, social exclusion, and poor quality of the residential environment have been negatively associated with aspects of positive mental health [58-60].

The reality of social health inequalities has been well established, and scientific inquiry has uncovered several mechanisms through which social determinants contribute to people's (ill-)health (e.g., via control over one's life and social capital); more research is now needed on how to influence these mechanisms to reduce inequalities $[61,62]$, particularly among vulnerable populations such as public housing tenants. Frohlich and Potvin [7] have suggested that a vulnerable population approach to intervention should have two characteristics: 1 ) be intersectoral, because social determinants of health are often located outside the health sector; and 2) involve the participation of the targeted population. Thus, any efforts toward reducing social health inequalities for public housing tenants should involve tenants themselves in describing the issue and in conceptualizing, implementing, and evaluating the intervention.

Flash on my neighborhood!, the intervention whose implementation and evaluation protocol is described in this article, incorporates these state-of-the art principles in a four-year multiphase community-based participatory action research strategy. Participatory action research is increasingly popular, but few empirical studies have focused on its real capacity to produce social change or the mechanisms through which it can generate its effects $[63,64]$. Flash on my neighborhood! aims to improve the positive mental health of public housing tenants (thereby reducing the social inequalities they face compared to the general population), through focusing on social determinants, such as environmental and policy changes that are needed to make public housing settings healthier environments. Flash on my neighborhood! is a placebased intervention that gets public housing tenants involved in critically assessing their own residential environment (its strengths and weaknesses, how it promotes or hinders their well-being), developing an action plan to improve the situation, and then in implementing and evaluating that plan.

Flash on my neighborhood! uses a collective empowerment strategy to foster person-environment congruence [65]. Collective empowerment is defined as "a united and systematic effort by a group to gain control over and improve their aggregated lives by defining problems, assets, solutions, and the processes by which change can occur, and by building individual and collective capacity that can energize the power and knowledge existing within the assembly" (p. 213) [66]. In line with this definition, a collective empowerment strategy should improve tenants' control over decisions that affect their life as well as their social capital.

Other place-based interventions targeting deprived neighborhoods have been examined empirically, but were found to be "unfocused, unsubstantial and shortterm" [67]. In Flash on my neighborhood!, the four-year collective effort of public housing tenants will be focused on a specific target: improving person-environment congruence [65], which represents the adequacy between their needs, capabilities, and aspirations on the one hand, and the residential environment's resources, demands, and opportunities on the other. Based on Horelli's model for locally-dependent populations [19], we conceptualized the residential environmental as having four distinct types of structures that can support congruence: 1) physical structures, or the built and natural environment (e.g., buildings, roads, and green spaces); 2) functional structures, which represent the services available, such as transportation, stores, leisure centers; 3) participatory structures, which refer to opportunities to participate in the political and social life of the community, for instance through volunteering, or to develop abilities through involvement in specific projects; and 4) sociocultural structures, which relate to the sense of community, mutual aid between neighbors, and the shared culture of the group.

Figure 1 presents the logic model of Flash on my neighborhood!. As shown in the model, the strategy involves a facilitation team accompanying public housing residents through a structured collective participation process, including a strengths and needs assessment, and the development, implementation, and monitoring of an action plan to address the needs for improvement. It is theorized that these activities will promote tenants' control over their environment as well as their social 


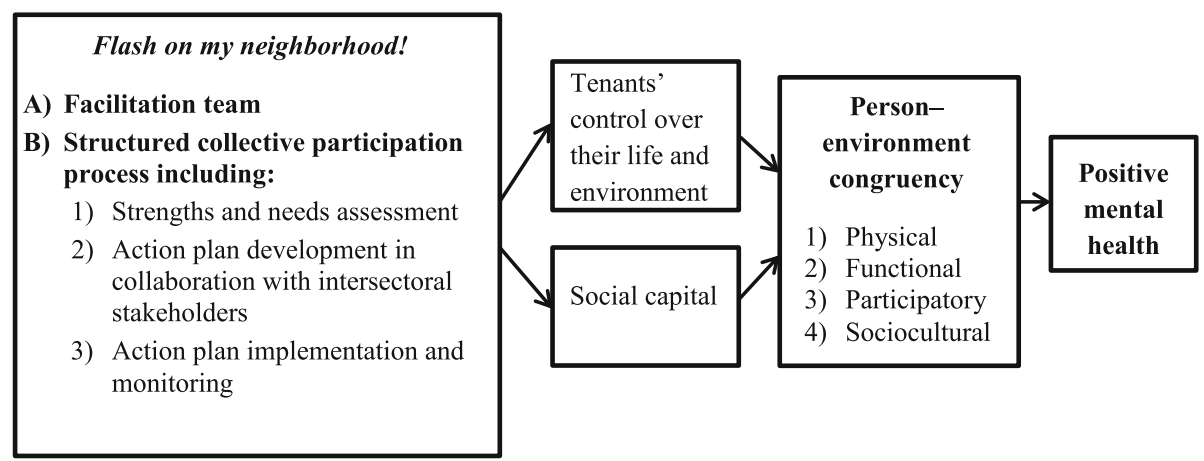

Fig. 1 Summary of the Flash on my neighborhood! logic model

capital, making them more likely to act towards improving the congruence of their environment, which in turn should promote their positive mental health.

\section{Study aims}

Implementation studies can provide "extremely relevant information that can be used in other settings, for the improvement in the delivery of other types of interventions" (p. 115) [62]. In that perspective, the aim of the present protocol is to: 1) evaluate the implementation of Flash on my neighborhood! in six public housing developments; and 2) determine the perceived effects on person-environment congruency and positive mental health among public housing tenants.

\section{Research questions}

The study aims to answer six questions: 1) How do contextual factors influence the intervention's implementation? 2) Which improvements in the residential environment are prioritized by public housing tenants? 3) Which planned improvements in the residential environment succeeded and which failed? 4) What are the contextual factors (e.g., urban vs. rural area, level of cultural diversity in the public housing setting, etc.) that played a role in the success or failure of the planned improvements? 5) Did the intervention improve tenants' perceived control over their environment and social capital? 6) Did tenants perceive improved person-environment congruency and positive mental health as a result of the intervention?

\section{Methods}

\section{Design}

The study uses a prospective, multiple case study design $[68,69]$, which allows for an in-depth investigation of complex changes in real contexts. Each unit of analysis (case) is composed of a public housing development, its tenants, the staff and managers of the city's housing agency, as well as stakeholders (staff, managers, and decision-makers) from community organizations and the municipal government of the areas in which the project is implemented. A multiple case study design is essential to evaluate a complex intervention such as Flash on my neighborhood! because it allows researchers to document the intervention's general functioning while also investigating how the contextual characteristics of the setting in each case influence its implementation [68]. Using the same method in multiple cases leads to an enhanced understanding of the phenomenon, and also increases the validity and generalizability of the results [70-72]. Similarities and differences are recorded, to develop significant patterns from the data [73].

\section{Settings}

The study takes place in six public housing developments in the province of Quebec, Canada: Montreal, Saint-Hyacinthe, Cowansville, Lévis, Gatineau, and Trois-Rivières. These six cases were selected through intentional sampling to maximize their diversity in terms of 1) city size (number of citizens), 2) size of the city's housing agency, 3) number of dwellings in the development, 4) type of tenants (families, one-person households, seniors or mixed), 5) building characteristics (high-rises $>4$ storeys, buildings $\leq 4$ storeys, townhouses), and 6) cultural diversity (see Table 1).

\section{Flash on my neighborhood! Intervention}

For tenants to develop control over the changes that they perceived as important, we chose to standardize the process rather than the content of the intervention [74, 75]. The intervention involves a facilitation team and a structured collective process including three phases: 1) Strengths and needs assessment; 2) Action plan development; and 3) Action plan implementation and monitoring.

\section{Facilitation team}

Each site is assisted by a facilitation team composed of two graduate students (in community psychology, social work, or psychoeducation) and one undergraduate 
Table 1 Characteristics of the settings

\begin{tabular}{llllll}
\hline City & Population & $\begin{array}{l}\text { Size of the city's } \\
\text { housing agency (units) }\end{array}$ & $\begin{array}{l}\text { Number of } \\
\text { dwellings }\end{array}$ & Tenants & Type of buildings \\
\hline Montreal & $>1,500,000$ & 30,385 & 177 & Families & $\begin{array}{l}1 \text { high-rise, } 3 \text { buildings, } 5 \\
\text { townhouses }\end{array}$ \\
St-Hyacinthe & $\pm 53,000$ & 668 & 119 & Families & 3 buildings, 48 townhouses \\
Cowansville & $\pm 13,000$ & 198 & 98 & Mixed & 9 buildings, 10 townhouses \\
Lévis & $\pm 140,000$ & 1263 & 84 & Single-person household & 3 buildings \\
Gatineau & $\pm 260,000$ & 3597 & 398 & Mixed & 3 high-rises \\
Trois-Rivières & $\pm 130,000$ & 1864 & 133 & Seniors & 1 high-rise
\end{tabular}

Buildings are $\leq 4$ storeys, while high-rises are $>4$ storeys

student (total $n=18$ ), supervised by the principal investigator (PI). The facilitation teams have to follow a structured protocol for each of the three steps to assure a rigorous implementation of the intervention and to enhance the reliability of the results in a multiple case study $[69,72,76]$. The facilitation team's role is to support tenants' capacity-building at each step of the process. They model how to organize and moderate a meeting and how to solve interpersonal conflicts. They also provide tenants practical tools for long-term use beyond the intervention, such as factsheets that show how to set realistic and achievable objectives and how to make an action plan. The facilitation team uses a gradual process of empowerment in which they provide more leadership in the first stages of the project, but transfer more and more responsibilities to tenants as it progresses. At the end of the project, tenants should be more autonomous in organizing citizen participation initiatives in their setting.

\section{Strengths and needs assessment}

This step aims to describe the assets and improvement needs in the residential environment of each setting. Four sequential activities will be performed for that purpose: a) recruitment and training of tenant researchers; b) a photovoice project (see [77] for a description of this activity in the Montreal setting); c) systematic neighborhood observation with a grid (see [78] for a description of this activity in the Montreal setting); and d) a household survey.

a) In each site, eight to twelve public housing tenants are recruited and trained to act as peer researchers, or what we call tenant researchers. The involvement of peer researchers is increasingly popular in public health [79], because it promotes capacity-building and empowerment of community members and increases data validity [79-81]. In the present study, various means are used to recruit tenant researchers: written invitations to each household, posters, outreach by the tenants' association, and information meetings.
Following best practices [79], tenant researchers will participate significantly in data collection, data analysis, data interpretation, and knowledge mobilization, as well as to in action plan development and implementation. They receive appropriate training (research ethics, theories of mental health and environment, photography). Over time, they develop other capabilities, such as content analysis, and writing and communication skills. A stipend of $\$ 20$ is given to each tenant researchers for their participation in the strengths and needs assessment activities.

b) In the photovoice activity, the tenant researchers are accompanied by the facilitation team through eight weekly meetings. The first two meetings consist in training on research ethics and photography, and an explanation of the study's concepts. Over the next four weeks, prior to meetings three to six, the tenant researchers take pictures of their residential environment, selecting two of them to bring to the following meeting for group discussion. These audio-recorded discussions help the group identify themes under which to classify the pictures. In the two final meetings, the tenant researchers finalize the thematic analysis, write captions for each of their pictures, and collaborate on organizing a public exhibit of their work. At the official opening for the exhibit, community stakeholders (such as the city mayor or housing agency director) are invited to acknowledge the work and perspectives of the tenant researchers. The photovoice process seeks to engage members of a community in collecting data about the community's strengths and weaknesses, to promote critical knowledge and dialogue concerning the community's important issues, and to reach decision-makers in order to produce social change [82].

c) During the systematic neighborhood observation activity, the tenant researchers assign a score of 0 (very unsatisfying) to 4 (very satisfying) to 64 elements in their residential environment based on their observation and appreciation of the quality of those elements. A two-member facilitation team 
accompanies the group through five weekly meetings. In the first meeting, a neighborhood observation grid (see [78]) is presented, and the tenant researchers form teams of two or three. Before each of the following four meetings, these small teams walk through their residential environment to complete the grid, section by section: 1) Public housing development; 2) Streets and buildings in the neighborhood; 3) Green spaces in the neighborhood;

4) Interpersonal relationships in the neighborhood and

5) Shops, community organizations, and services.

During the group meetings, the teams present their score for each item as well as justifications for their choice. Afterwards, the group discusses to agree on a single collective score for each item. A facilitation technique adapted from the Canadian Institutes of Health Research grant evaluation technique is used to prevent discussions from escalating. Each tenant researcher can confidentially allocate a parallel score equivalent to 0.5 points over or under the collective score. This ensures that every tenant researcher feels that their opinion is respected, while making the collective decision-making process easier.

d) In each household, one adult is invited to complete a survey on their residential environment and positive mental health. The survey includes items on positive mental health (a validated scale, [83]), personenvironment fit (a questionnaire designed for the purpose of the project; validation underway), individual control ([84]), collective empowerment (inspired by existing items $[85,86]$ ), and sense of community, (Saïas $\mathrm{T}$, Loomis C, Beck F: Validation of the French Version of the Brief Sense of Community Index, submitted) as well as open-ended questions on tenants' talents, passions, and projects that contribute to their well-being. Tenant researchers and/or the tenants' associations are invited to design their own questions (e.g. about tenants' willingness to participate in different activities) in addition to the standardized scales, to inform their activities and the next phase of the project (action plan). The one-hour survey is verbally administered by a university research assistant at the participants' home or in a quiet confidential space, as participants prefer. Each participant receives a $\$ 10$ compensation for their time. Extensive recruitment efforts are made during the data collection period. For example, tenant researchers help distribute an invitation to every household. They also help publicize the survey through ads posted in the public housing development.

\section{Action plan development}

Three sequential activities, facilitated by two research assistants and occasionally the PI, are organized to develop a one-year action plan. First, a half-day collective forum is organized by the tenant researchers. This event aims to share the results of the strengths and needs assessment with the other tenants and community stakeholders, and to identify the issues that will be addressed in the upcoming year, implementing principles from the participative urbanism perspective [87, 88]. Tenant researchers have complete control over the organization of the forum: they choose the content, they write and distribute the invitations, they organize the activities for adults and children during the event, etc. They are encouraged to ask other tenants to volunteer and to use creative strategies to maximize the participation rate to the collective forum (such as participation prizes, entertainment for children, free snacks and beverages, music). Each hour of volunteering is formally recognized through citizen participation certificates that mention how many hours the person has invested and what kind of tasks were accomplished. These certificates not only serve to underline the value of tenants' contributions, but also to provide a record of the skills that they have developed through the project.

During the forum, tenant researchers present the four or five main themes that have emerged from the strengths and needs assessment phase, as identified in collaboration with the research team after having analyzed the results. Themes are then discussed in small groups between attendees, facilitated by a university student, with the goal of engaging attendees in interpreting the results related to the theme and in suggesting actions that should be implemented to improve the residential environment. Each small group is invited to share their action ideas with the larger group, which then votes to identify priority actions for each theme.

After the forum, the second activity consists in an interactive session given by the principal investigator about basic principles for producing change (inspired by [89]). Finally, the third activity consists of two meetings facilitated by the research team to elaborate the action plan with tenants, based on the priorities identified during the forum and the principles learned during the interactive session. Several strategies are used to involve more tenants in the action plan development activity, including reaching out to every tenant who attended the forum and sending personalized invitation letters to every tenant who indicated in the survey that they were willing to share their talents and passion with their neighbors.

The action plan describes specific objectives related to each of the two top priorities for every theme, manageable steps to follow to achieve those objectives, deadlines for each step, as well as resources and partners that could be helpful and potential pitfalls to avoid. Before the action plan is launched, it is presented by the tenants, to the housing agency employees and managers, as 
well as to other relevant community stakeholders to collect their comments and suggestions. However, the action plan belongs to the tenants, with the housing agency and other stakeholders being viewed as potential allies in its realization.

\section{Action plan implementation and monitoring}

The next phase is the implementation of the action plan over a 12-month period. During that time, monthly meetings are organized with the tenants to follow up on the previous month's achievements and to share the tasks planned for the coming month. Progress is celebrated, problems are discussed, and the plan is adjusted as needed. The community's progress is reviewed regularly by collecting objective and subjective information from participating tenants and stakeholders on four indicators: 1) tenants' involvement in their setting (number of people involved and number of hours devoted to the project); 2) quality of the social relationships among the tenants; 3) tangible improvements in the residential settings related to the project; 4) relationships with community partners and allies. As time goes by, tasks initially performed by the facilitation team (e.g., organizing meetings, etc.) are progressively entrusted to the tenants and their allies to encourage them to become autonomous by the end of the project.

\section{Intervention evaluation}

The study has received approval from the Ethics board of the Université du Québec à Montréal. A mixed-method evaluation was chosen for data collection and analysis. One strength of multiple case studies is the use of multiple data sources, which allows for triangulation and identifying potential convergence among the results [69].

To that end, the evaluation includes data from questionnaires, qualitative interviews, the research team's observations (e.g., regular journal entries by facilitators), and review of documents, in order to capture: a) contextual factors (tenants' previous experience of participation; history of the public housing development, etc.), b) activities that take place and priorities from the action plan that are implemented, and c) achievement of short- and mid-term outcomes (objective and perceived improvements in the quality of the residential setting, both physically and in terms of mental health and social capital).

Each tenant researcher completes questionnaires at the beginning of the photovoice process (pre-test) as well as after the public exhibit (three to four months later; post-test) to evaluate their self-reported positive mental health [83], personal control [84], collective empowerment (inspired by existing items $[85,86]$ ), and sense of community (Saïas T, Loomis C, Beck F: Validation of the French Version of the Brief Sense of Community Index, submitted). Sociodemographic characteristics are collected as well. The post- test also includes a scale on perceived group dynamics, including items inspired from an existing scale from Moos $[90,91]$. After the photovoice project, semi-structured qualitative interviews are conducted with tenant researchers to document their experience and the impact they perceive the project has had on them and on their neighbors up to that point. At the end of the action plan implementation phase, additional interviews will be conducted with tenants, as well as with housing agency managers and staff, to document the perceived impacts of the intervention on the tenants and on the residential environment.

Throughout the project, facilitation team members and the study coordinator complete a research journal entry after each interaction with tenants. They note their observations of the interactions with tenants, and between tenants and stakeholders. The meeting recordings, the pictures taken during the photovoice project, the scores obtained on the 64 environmental elements of the observation grid, the quantitative data collected in the household survey, the action plans, and meeting proceedings are all used to inform the evaluation.

\section{Data analysis}

A cross-case analysis method will be followed [68, 71], consisting in four steps: 1) organizing each site's data in a detailed case report; 2) using matrices and tables to identify key themes in each case; 3) examining the similarities and differences in these key themes to establish meaningful patterns; and 4) forming general explanations concerning the identified patterns. This type of analysis is a funnel process that serves to make sense out of a large quantity of information originating from multiple different sites. The ultimate goal is to generate explanations that will enhance our understanding of the phenomenon being studied. Each step represents an extension of the previous step, while the process remains iterative.

In the first step, each case is treated individually $[68,71]$. The sociodemographic questionnaires, tenant researchers' captions, interviews, meeting proceedings and recordings, and journal entries are all transcribed and uploaded along with the photos into the NVivo software application. A thematic analysis is performed in the following steps: gaining familiarity with the data; coding the data; looking for themes; revising the themes; defining and naming the themes [92, 93]. Quantitative data (survey answers, observation grid ratings) are analyzed using descriptive statistics, applying inferential statistical tests such as ANOVA to compare between the different implementation sites, and repeated-measures $\mathrm{t}$-tests to compare pre- and post-test questionnaires.

Treating the data case by case, all of the data is analyzed and observations are recorded. Next, the results that are relevant to the research questions are coded systematically. When the coding is finished, a list of codes 
and associated quotes is created based on the qualitative data. This list is used to regroup the codes in more general themes. The themes are revised with reference to the list of codes and raw data to ensure that all the relevant data is included under the proposed themes. Finally, the themes are named and defined in terms of their contribution to the research questions [92, 93]. The results are collected in a case report. The six case reports each contain a description of the public housing development site under study, as well as the themes and quotes relevant to the research questions.

In the second stage, the researchers ensure they gain an understanding of each case in-depth before proceeding to a cross-case analysis [68]. To do so, each case report is read thoroughly. During this reading, a note matrix is completed, to pick out the elements that are key to answering the research questions [68, 71]. This step reduces the quantity of information that will be used to perform the cross-case analysis, while preserving the most important elements [68].

In the next step, once the matrices are completed, patterns of similarities and differences between the cases are highlighted. A comparison grid is filled out to better visualize these patterns $[68,71]$. Certain themes will be found in all cases, while others will represent atypical themes, specific to one case but nevertheless worth reporting (Stake, 2006). The grid makes it possible to rapidly indicate the scope of each theme across the different cases while also presenting the context specific to each case.

In the final step, general explanations are formed using the patterns identified in the previous step. Particular attention is given to understanding how the patterns can best answer the research questions [68]. The comparison grid is reviewed to produce a summary grid containing the general explanations. This is an opportunity to reorganize, recombine, and elaborate on the general explanations. At this stage, efforts should be made to synthesize the findings [68]. The elements leading to the general explanations should be thoroughly evaluated. While revising the general explanations, it is important to reflect on the potential relationships between them. Are certain explanations linked? Does this add to their relevance, or does it give one explanation more weight?

\section{Methodological rigor}

The methodological rigor of the multiple case study approach is sometimes called into question $[69,76]$. However, several strategies can be put in place to ensure the study is highly rigorous [69].

\section{Construct validity}

Construct validity corresponds to the degree with which a study examines what it intends to examine [94]. Case studies are sometimes perceived as somewhat subjective [76]. To ensure construct validity in a case study, it is recommended to precisely define the concepts [69]. In the present study, residential environment is defined using a recognized theoretical model [19]. Also, triangulation of the data can reduce the subjectivity of interpretations $[68,69,76]$. When conducting a multiple case study, triangulation is performed within each case by using multiple data sources and across cases by verifying the convergence or divergence of results in different contexts [68].

\section{Internal validity}

Internal validity refers to the logical interpretation of data and therefore to the legitimacy of the study's conclusions [76]. To ensure a correct interpretation of the data, a member-checking procedure [68] will take place at two crucial moments of the data analysis. The detailed case reports will be submitted to members of the facilitation team and tenant researchers for each case [70], who will validate the reports by suggesting modifications or clarifications. At the end of the analysis, when general explanations are formed, a synthesis will again be submitted to stakeholders from each case.

\section{External validity}

External validity corresponds to the degree to which a study's results can be generalized [94]. Case studies do not aim to provide statistical generalization, which means that data from a case study does not lend itself to conclusions about an entire population [76]. The objective is rather analytical generalization, which is to generalize empirical observations to a build theory [69, 76]. In the present study, the empirical observations will contribute to a theory of the transaction between public housing tenants and their residential environment and how participatory interventions can help tenants take control to improve this transaction. A cross-case analysis including four to ten cases is considered a solid basis for analytical generalization [76]. Choosing cases with varied characteristics, as has been done in the present study, also promotes external validity [95].

\section{Fidelity}

Fidelity represents the possibility of replicating a study and obtaining the same results. In the present study, fidelity was strengthened by creating a multiple case study protocol to ensure a certain homogeneity in the intervention implementation and data collection methods across the six sites $[69,72,76]$. Furthermore, the entirety of the data, including an audit trail of all analyses performed, will be retained in a database, making it available for a later replication study $[69,72,76]$. 


\section{Discussion}

Flash on my neighborhood! is the first population health intervention study that focuses on improving the positive mental health of public housing tenants. There is little knowledge concerning successful strategies for increasing vulnerable populations' control over their environment and social capital, especially in public housing settings, where people are at high risk of experiencing social and psychological challenges. Flash on my neighborhood! provides an innovative opportunity to study a structured intervention process for developing public housing tenants' collective empowerment in multiple settings, also contributing to a theoretical framework of contextual factors that facilitate or impede such an intervention process. As public housing authorities are generally relatively unfamiliar with tenant empowerment practices, they tend to form a highly hierarchical structure within which tenants have little real control over the choice of their dwelling and many aspects of their residential environment [96]. Thus, tenants are often captive of a stigmatized residential environment, bound by numerous rules (which they have not contributed to formulating), and denied direct contact with landlords and decision-makers.

By explicitly focusing on increasing residents' control over their environment and social capital, Flash on my neighborhood! targets two crucial social determinants of health in order to contribute to an emerging "science of solutions" to reduce social health inequities [62]. The study will also make a significant methodological contribution through the use and validation of a person-environment congruency questionnaire and a systematic observation grid that are adapted to the public housing setting.

Finally, the results will also inform practitioners regarding public housing tenants' priorities for improving their residential settings, and will provide participatory intervention strategies to turn such settings into environments that promote mental health. We will know more about the conditions to put in place to help these residents achieve their goals and aspirations, and thus their well-being. There are many public housing settings around the world; the results of this study will help policy-makers, managers, and staff design environments that promote tenants' mental health, thereby reducing the inequities they face.

\section{Endnotes}

${ }^{1}$ Although the quality of the built environment is still perceived to be an issue (e.g., [97]), in Québec, Canada, multi-storey public housing buildings represent the exception rather than the rule.

\section{Acknowledgements}

The authors would like to acknowledge the collaboration of the six public housing agencies from the province of Québec who accepted to partner with the research team to implement and evaluate this intervention strategy. We also wish to thank the peer-researchers involved in the study as well as the participating public housing communities.

\section{Funding}

The study was supported by an Insight Development Grant (\#430-201400483) and a Development Grant (\#435-2016-1088) from the Social Sciences and Humanities Research Council of Canada.

\section{Availability of data and materials}

The datasets used and/or analysed during the current study are available from the corresponding author on reasonable request.

\section{Authors' contributions}

$\mathrm{JH}, \mathrm{SC}$ and SR designed the study with the insights of all the co-authors listed on this manuscript. All are co-investigators involved in this research. As director of the study, $\mathrm{JH}$ wrote the main sections of the manuscript. SC and SR completed the manuscript. XL, PM, JT and TS provided feedback to improve the manuscript. All authors read and approved the final manuscript.

\section{Ethics approval and consent to participate}

Ethical approval (402 e 2017) was granted by the institutional research ethics board for research involving human participants at Université du Québec à Montréal, Canada. The participants must sign a written consent form which is thoroughly explained to them before taking part in the study.

Consent for publication

Not applicable.

\section{Competing interests}

The authors declare that they have no competing interests.

\section{Publisher's Note}

Springer Nature remains neutral with regard to jurisdictional claims in published maps and institutional affiliations.

\section{Author details}

${ }^{1}$ Department of Psychology, Université du Québec à Montréal, C.P. 8888, succ. Centre-ville, Montréal, Québec H3C 3P8, Canada. ²Department of Psychology, Wilfrid Laurier University, Waterloo, Canada. ${ }^{3}$ Institut national de la recherche scientifique, Centre Urbanisation Culture Société, Montreal, Canada. ${ }^{4}$ Urban planning, Université de Montréal, Montréal, Canada. ${ }^{5}$ Social Work, Université de Sherbrooke, Sherbrooke, Canada.

Received: 7 June 2017 Accepted: 11 September 2017

Published online: 25 September 2017

References

1. Société d'habitation du Québec. (2014). L'habitation en bref 2014. [Housing in short 2014]. Quebec city, : Author.

2. Digenis-Bury EC, Brooks DR, Chen L, Ostrem M, Horsburgh CR. Use of a population-based survey to describe the health of Boston public housing residents. Am J Public Health. 2008;98:85-91.

3. Filakti H, Fox J. Differences in mortality by housing tenure and car access from the OPCS longitudinal study. Popul Trends. 1995;81:27-30.

4. Hiscock R, Macintyre S, Kearns A, Ellaway A. Residents and residence: factors predicting the health disadvantage of social renters compared to owneroccupiers. J Soc Issues. 2003; https://doi.org/10.1111/1540-4560.00076.

5. Ludwig K, Duncan GJ, Gennetian LA, Katz LF, Kessler RC, Kling JR, et al. Neighborhood effects of the long-term well-being of low-income adults. Science. 2012;337(6101):1505-10. https://doi.org/10.1126/science.1224648.

6. Société d'habitation du Québec. (2015). La santé des résidents de HLM: analyse comparative de la santé de la population faible revenu. [the health of public housing residents: comparative analysis of the health of the lowincome population]. Quebec City: Author.

7. Frohlich $\mathrm{KL}$, Potvin L. Transcending the known in public housing practice: the inequality paradox: the population approach and vulnerable populations. Am J Public Health. 2008;98(2):216-21.

8. Evans GW, Wells NM, Moch A. Housing and mental health: a review of the evidence and a methodological and conceptual critique. J Soc Issues. 2003; 59(3):475-500 
9. Motley CM, Perry VG. Living on the other side of the tracks: an investigation of public housing stereotypes. J Public Policy Mark. 2013;32(Special Issue): 48-58.

10. Skobba K, Bruin MJ. Examining public housing stereotypes and building intercultural competence through service-learning. Fam Consum Sci Res J. 2016:44:345-59.

11. Hayward E, Ibe C, Young JH, Potti K, Jones P 3rd, Pollack CE, et al. Linking social and built environmental factors to the health of public housing residents: a focus group study. BMC Public Health. 2015; https://doi.org/10. 1186/s12889-015-1710-9.

12. Baker MG, Zhang J, Blakely T, Crane J, Saville-Smith K, Howden-Chapman P. Collaborating with a social housing provider supports a large cohort study of the health effects of housing conditions. BMC Public Health. 2016; https://doi.org/10.1186/s12889-016-2730-9.

13. Rosenfeld L, Chew GL, Rudd R, Emmons K, Acosta L, Perzanowski M, et al. Are building-level characteristics associated with indoor allergens in the household? J Urban Health. 2011;88:14-29.

14. Dunn JR, Hayes M, Hulchanski JD, Hwang SW, Potvin L. Housing as a socioeconomic determinant of health: a Canadian research framework. In: Howden-Chapman P, Carroll P, editors. Housing \& health: research, policy and innovation. Wellington, NZ: Steele Roberts; 2004. p. 12-39.

15. Fisher $M$, Baum $F$. The social determinants of mental health: implications for research and health promotion. Aust N Z J Psychiatry. 2010;44:1057-63.

16. Apparicio $P$, Séguin AM. Measuring the accessibility of services and facilities for residents of public housing in Montreal. Urban Stud. 2006;43:187-211. https://doi.org/10.1080/00420980500409334.

17. Inagami S, Cohen DA, Finch BK. Non-residential neighborhood exposures suppress neighborhood effects on self-rated health. Soc Sci Med. 2007;65(8): 1779-91.

18. Vallée J, Cadot E, Roustit C, Parizot I, Chauvin P. The role of daily mobility in mental health inequalities: the interactive influence of activity space and neighbourhood of residence on depression. Soc Sci Med. 2011;73(8):1133-44.

19. Horelli L. Environmental human-friendliness as a contextual determinant for quality of life. Eur Rev Appl Psychol. 2006;56:15-22. https://doi.org/10.1016/j. erap.2005.02.012.

20. Marmot M. The health gap: the challenge of an unequal world. London: Bloomsbury; 2015

21. Wilkinson RG, Pickett $K$. The spirit level: why equality is better for everyone. London: Penguin; 2010.

22. Banks J, Marmot M, Oldfield Z, Smith J. Disease, and disadvantage in the United States and in England. JAMA. 2006;295:2037-45.

23. Glover JD, Hetzel DM, Tennant SK. The socioeconomic gradient and chronic illness and associated risk factors in Australia. Aust N Z Health Policy. 2004;1:8

24. Kosidou K, Dalman C, Lundberg M, Hallqvist J, Isacsson G, Magnusson C. Socioeconomic status and risk of psychological distress and depression in the Stockholm public health cohort: a population-based study. J Affect Disord. 2011;134:160-7

25. Melchior M, Chastang JF, Head J, Goldberg M, Zins M, Nabi H, et al. Socioeconomic position predicts long-term depression trajectory: a 13-year follow-up of the GAZEL cohort study. Mol Psychiatry. 2013;18:112-21.

26. Beckie TM. A systematic review of allostatic load, health, and health disparities. Biol Res Nurs. 2012;14(4):311-46.

27. Braveman P, Gottlieb L. The social determinants of health: It's time to consider the causes of the causes. Public Health Rep. 2014;129(Suppl 2):19-31.

28. Braveman P, Egerter S, Williams DR. The social determinants of health: coming of age. Annu Rev Public Health. 2011;32:381-98.

29. Chen E, Miller GE. Socioeconomic status and health: mediating and moderating factors. Annu Rev Clin Psychol. 2013;9:723-49.

30. Chrousos GP. Stress and disorders of the stress system. Nat Rev Endocrin. 2009:5:374-81

31. Cunliffe VT. The epigenetic impacts of social stress: how does social adversity become biologically embedded? Epigenomics. 2016;8(12):1653-69.

32. Marmot M. Status syndrome: how your social standing affects our health and longevity. Bloomsbury: London, UK; 2004.

33. Matthews KA, Gallo LC. Psychological perspectives on pathways linking socioeconomic status and physical health. Annu Rev Psychol. 2011;62:501-30

34. Uphoff EP, Pickett KE, Cabieses B, Small N, Wright J. A systematic review of the relationships between social capital and socioeconomic inequalities in health: a contribution to understanding the psychosocial pathway of health inequalities. Int J Equity Health. 2013; https://doi.org/10.1186/1475-9276-12-54.
35. Bourdieu P. The forms of capital. In: Richardson JG, editor. Handbook of theory and research for the sociology of education. New York: Greenwood: 1986. p. 241-58.

36. Sen A. Development as freedom. Oxford, UK: University Press; 1999.

37. Whitehead M, Pennington A, Orton L, Nayak S, Petticrew M, Sowden A, et al. How could differences in "control over destiny" lead to socioeconomic inequalities in health? A synthesis of theories and pathways in the living environment. Health Place. 2016;39:51-61.

38. Ahluwalia JS, Nollen N, Kaur H, James AS, Mayo MS, Resnicow K. Pathway to health: cluster-randomized trial to increase fruit and vegetable consumption among smokers in public housing. Health Psychol. 2007;26(2):214-21.

39. Andrews JO, Mueller M, Dooley M, Newman SD, Magwood GS, Tingen MS. Effect of a smoking cessation intervention for women in subsidized neighborhoods: a randomized controlled trial. Prev Med. 2016;90:170-6.

40. Gans KM, Gorham G, Risica P, Dulin-Keita A, Dionne L, Gao T, et al. A multilevel intervention in subsidized housing sites to increase fruit and vegetable access and intake: rationale, design and methods of the "live well, viva Bien" cluster randomized trial. BMC Public Health. 2016; https://doi.org/10.1186/ s12889-016-3141-7.

41. McNeill LH, Coeling M, Puleo E, Suarez EG, Bennett GG. Emmons KM colorectal cancer prevention for low-income, sociodemographically-diverse adults in public housing: baseline findings of a randomized controlled trial. BMC Public Health. 2009;9:353.

42. Quintiliani LM, Debiasse MA, Branco JM, Bhosrekar SG, Rorie JA, et al. Enhancing physical and social environments to reduce obesity among public housing residents: Rationale, trial design, and baseline data for the Healthy Families Study. Contemp Clin Tr. 2014;39:201-10.

43. O'Mara-Eves A, Brunton G, McDaid D, Oliver S, Kavanagh J, Jamal F, et al. Community engagement to reduce inequalities in health: A systematic review, meta-analysis and economic analysis. Public Health Res. 2013; 1(4) doi:https://doi.org/10.3310/phr01040. PMID: 25642563.

44. World Health Organization. Mental health: A state of well-being. http://www. who.int/features/factfiles/mental_health/en/ (2014). Accessed 16 Apr 2017.

45. Azevedo Da Silva M, Singh-Manoux A, Brunner EJ, Kaffashian S, Shipley MJ, et al. Bidirectional association between physical activity and symptoms of anxiety and depression: the Whitehall II study. Eur J Epidemiol. 2012;27(7):537-46.

46. Bazo-Alvarez JC, Peralta-Alvarez B-OA, Alvarado GF, Miranda JJ. Tobacco consumption and positive mental health: An epidemiological study from a positive psychology perspective. BMC Psychol. 2016;May;4:4-22.

47. Brumpton $B$, Langhammer A, Romundstad $P$, Chen $Y$, Mai XM. The associations of anxiety and depression symptoms with weight change and incident obesity: the HUNT study. Int J Obes. 2013;37(9):1268-74.

48. Trudel-Fitzgerald C, Tworoger SS, Poole EM, Williams DR, Kubzansky LD. Prospective changes in healthy lifestyle among midlife women: when psychological symptoms get in the way. Am J Prev Med. 2016;51:327-35.

49. Tedeschi GJ, Cummins SE, Anderson CM, Anthenelli RM, Zhuang YL, Zhu SH. Smokers with self-reported mental health conditions: a case for screening in the context of tobacco cessation services. PLoS One. 2016; https://doi.org/ 10.1371/journal.pone.0159127.

50. Keyes CLM. Mental illness and/or mental health? Investigating axioms of the complete state model of health. J Consult Clin Psychol. 2005;73(3):539-48.

51. Westerhof GJ, Keyes CLM. Mental illness and mental health: the two continua model across the lifespan. J Adult Dev. 2010;17(2):110-9.

52. Keyes CLM, Dhingra SS, Simoes EJ. Change in level of positive mental health as a predictor of future risk of mental illness. Am J Public Health. 2010; 100(12):2366-71

53. Ryff CD. Happiness is everything, or is it? Explorations on the meaning of psychological well-being. J Pers Soc Psychol. 1989;57(6):1069-81.

54. Cohen R, Bavishi C, Rozanski A. Purpose in life and its relationship to allcause mortality and cardiovascular events: a meta-analysis. Psychosom Med. 2016;78(2):122-33.

55. Friedman EM, Hayney M, Love GD, Singer BH, Ryff CD. Plasma interleukin-6 and soluble IL-6 receptors are associated with psychological well-being in aging women. Health Psychol. 2007:26(3):305-13.

56. Keyes CL, Simoes EJ. To flourish or not: positive mental health and all-cause mortality. Am J Public Health. 2012;102:2164-72.

57. Kim ES, Sun JK, Park N, Peterson C. Purpose in life and reduced incidence of stroke in older adults: 'The Health and Retirement Study'. J Psychosom Res. 2013;May;74:427-32.

58. Dreger S, Buck C, Bolte G. Material, psychosocial and sociodemographic determinants are associated with positive mental health in Europe: a cross- 
sectional study. BMJ Open. 2014; https://doi.org/10.1136/bmjopen-2014005095.

59. Gale CR, Dennison EM, Cooper C, Sayer AA. Neighbourhood environment and positive mental health in older people: the Hertfordshire cohort study. Health Place. 2011;17(4):867-74.

60. Jones R, Heim D, Hunter S, Ellaway A. The relative influence of neighbourhood incivilities, cognitive social capital, club membership and individual characteristics on positive mental health. Health Place. 2014;28:187-93.

61. Hawe P, Potvin L. What is population health intervention research? Can J Public Health. 2009;100(1):18-114.

62. Potvin L, Pettigrew M, Cohen ERM. Population health intervention research: developing a much needed science of solutions. Prev Med. 2014;61:114-5.

63. Jagosh J, Bush PL, Salsberg J, Macaulay AC, Greenhalgh T, Wong G, et al. A realist evaluation of community-based participatory research: partnership synergy, trust building and related ripple effects. BMC Public Health. 2015; https://doi.org/10.1186/s12889-015-1949-1.

64. Oetzel JG, Zhou C, Duran B, Pearson C, Magarati M, Lucero J, et al. Establishing the psychometric properties of constructs in a community-based participatory research conceptual model. Am J Health Promot. 2015;29(5):e188-202.

65. Moser G. Quality of life and sustainability: toward person-environment congruity. J Environ Psychol. 2009:29:351-7.

66. Reininger B, Martin DW, Ross M, Sinicrope PS, Dinh-Zarr T. Advancing the theory and measurement of collective empowerment: a qualitative study. Int Q Community Health Educ. 2005-2006;25:211-38

67. Droomers M, Harting J, Jongeneel-Grimen B, Rutten L, van Kats J, Stronks K. Area-based interventions to ameliorate deprived Dutch neighborhoods in practice: does the Dutch District approach address the social determinants of health to such an extent that future health impacts may be expected? Prev Med. 2014;61:122-7.

68. Stake RE. Multiple case study analysis. New York, NY: The Guilford Press; 2006.

69. Yin RK. Case study research: Design and Methods. 5th ed. Thousand Oaks, CA: SAGE Publications; 2014.

70. Campbell R, Ahrens CE. Innovative community services for rape victims: an application of multiple case study methodology. Am J Community Psychol. 1998;26(4):536-71.

71. Chmiliar L. Multiple-case designs. In: Mills AJ, Durepos G, Wiebe E, editors. Encyclopedia of case study research. Thousand Oaks, CA: SAGE Publication; 2010. p. 583-5.

72. Lee KS, Chavis DM. Cross-case methodology: bringing rigour to community and systems change research and evaluation. J Community Appl Soc. 2012; 22:428-38.

73. Stake RE. The art of case study research. Thousand Oaks, CA: Sage Publications Inc; 1995.

74. Hawe P, Shiell A, Riley T. Complex interventions: how "out of control" can a randomised controlled trial be? Brit Med J. 2004;328:1561-3.

75. Patton GC, Bond L, Carlin JB, Thomas L, Butler H, Glover S, et al. Promoting social inclusion in schools: a group-randomized trial of effects on student health risk behavior and well-being. Am J Public Health. 2006;95(9):1582-7.

76. Gibbert M, Ruigrok W, Wicki B. What passes as a rigorous case study? Strategic Manage J. 2008;29(13):1465-74.

77. Houle J, Coulombe S, Radziszewski S, Boileau G, Morin P, Leloup X, Bohémier $H$, Robert S.Public housing tenants' perspective on residential environment and positive well-being: An empowermentbased Photovoice study and its implication for social work. J Soc Work. 2016. doi:10.1177/1468017316679906.

78. Coulombe S, Radziszewski S, Morin P, Leloup X, Bohémier H, Houle J. Using neighborhood observation to support public housing tenants' empowerment. Action Res. 2017. doi:10.1177/1476750317695411.

79. Roche B, Guta A, Flicker S. Peer research in action I: models of practice. Wellesley Institute: Toronto, Canada; 2010.

80. Cargo M, Mercer SL. The value and challenges of participatory research: strengthening its practice. Annu Rev Public Health. 2008;29:325-50.

81. Minkler M, Wallerstein N. Introduction to community based participatory research. In: Minkler M, Wallerstein N, editors. Community-based participatory research for health. San Francisco, CA: Jossey-Bass; 2008. p. 3-26.

82. Wang C, Burris M. Photovoice: concept, methodology, and use for participatory needs assessment. Health Educ Behav. 1997;24(3):369-87.

83. Lamers SM, Westerhof GJ, Bohlmeijer ET, ten Klooster PM, Keyes CL. Evaluating the psychometric properties of the mental health continuumshort form (MHC-SF). J Clin Psychol. 2011;67(1):99-110.

84. Pearlin LI, Schooler C. The structure of coping. J Health Soc Behav. 1978;19: $2-21$.
85. Israel B, Checkoway B, Schulz A, Zimmerman M. Health education and community empowerment: conceptualizing and measuring perceptions of individual organizational and community control. Health Educ Behav. 1994; 21(2):149-70.

86. Speer P, Peterson NA. Psychometric properties of an empowerment scale: testing cognitive, emotional, and behavioral domains. Soc Work Res. 2000; 24(2):109-18.

87. Bratteteig T, Bødker K, Dittrich Y, Mogensen P, Simonsen J. Methods: organizing principles and general guidelines for participatory design projects. In: Simonsen J, Robertson T, editors. Routledge international handbook of participatory design. New York, NY: Routledge; 2013. p. 117-44.

88. Thwaites K, Mathers A, Simkins I. Socially restorative urbanism: the theory, process and practice of experiemics. New York, NY: Routledge; 2013.

89. Heath C, Health D. Switch. How to change things when change is hard. Toronto: Random House Canada; 2010

90. Moos R. Group environment scale: Manual. Palo Alto: Consulting Psychologists Press; 1981.

91. Ménard R. Le climat social dans les équipes de réeducation de Boscoville. Montréal, Canada: Groupe de Recherche sur I'Inadaptation Juvénile, University de Montréal; 1974.

92. Braun V, Clarke V. Using thematic analysis in psychology. Qual Res Psychol. 2006:3(2):77-101.

93. Braun V, Clarke V, Terry G. Thematic analysis. In: Lyons A, editor. Qualitative research in clinical and health psychology. New York, NY: Palgrave Macmillan; 2014. p. 95-113.

94. Wludyka P. Study designs and their outcomes. In: Macha K, McDonough JP, editors. Epidemiology for advanced nursing practice. London, UK: Jones \& Bartlett Learning; 2012. p. 81-114.

95. Burns JMC. Cross-case synthesis and analysis. In: Mills AJ, Durepos G, Wiebe E, editors. Encyclopedia of case study research. Thousand Oaks, CA: SAGE Publications, Inc; 2010. p. 583-5.

96. Thurber A, Fraser J. Disrupting the order of things: public housing tenant organizing for material, political and epistemological justice. Cities. 2016;57: $55-61$.

97. Leloup X, Morin P. Les modes d'allocation du logement social ont-ils un effet sur le bien-être et la santé des familles? Une comparaison des programmes d'habitation à loyer modique (HLM) et de supplément au loyer (PSL) à Montréal. [Do the modes of social housing allocation affect the families' health and well-being? A comparison of public housing program and the rend supplement program in Montreal], Ottawas: Canada Mortgage and Housing Corporation; 2012.

\section{Submit your next manuscript to BioMed Central and we will help you at every step:}

- We accept pre-submission inquiries

- Our selector tool helps you to find the most relevant journal

- We provide round the clock customer support

- Convenient online submission

- Thorough peer review

- Inclusion in PubMed and all major indexing services

- Maximum visibility for your research

Submit your manuscript at www.biomedcentral.com/submit
) Biomed Central 